\title{
A Model for Replacing the Kaliba Dam Based on Multi-dam System
}

\section{Yajie $\mathrm{Xu}$}

\section{School of North China Electric Power University, Baoding 071003, China \\ Yajie_Ncepu@163.com}

\begin{abstract}
Considering the Kariba Dam's current dangerous situation, our team primarily analyses the three available options, and then explores the effect from a system of dams to the Zambezi River.a Dam Site Selection Model(DSSM)is established by constructing two initial sub-models named Basic Location Model (BLM) and Optimized Addressing Model (OAM) respectively. In BLM, based on the principle of building dams at densely packed contours, we get a series of contour by Global Mapper and determine 25 original locations .In OAM, based on overall water management capabilities which framed by reservoir capacity and Dam Cost Equation which founded by Dam Geometries Equation, the position of the dam is a variable, by 0-1 Integer Programming, our team acquire the position coordinates of 15 dams.
\end{abstract}

Keywords: Kariba Dam ; A system of dams;0-1 Integer Programming;

\section{Introduction}

Dams are used to control and distribute natural surface water and groundwater. It can provide flood control capacity, can irrigation in the dry season.Obviously, Kariba Dam burdens these functions.In addition,the existing Kaliba dam has a large storage capacity.A 2015 report by the Institute of Risk Management of South Africa included a warning that the dam is in dire need of maintenance. So we're going to removing the Kariba Dam and replacing it with a series of ten to twenty smaller dams along the Zambezi River.

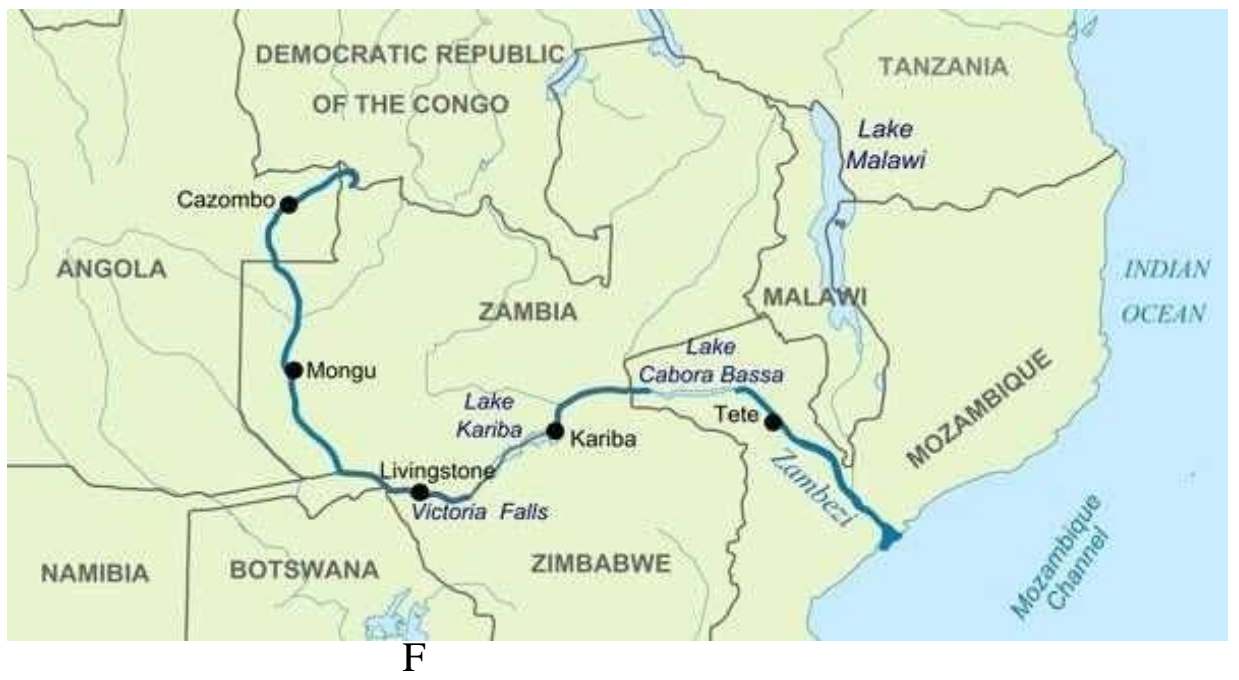

Fig.1 The Kariba Dam ${ }^{[2]}$ 


\section{Dam Site Selection Model}

\subsection{Dam Geometries Equation}

Most of the Zambezi River channel cut through the sandstone layer,and part of the river cut through the basalt layer. The river bed of the Zambezi River is complex. It is not easy to model and solve later. So, we assume that the river cross-section is approximately rectangular.

The length of the cross-section of the channel at the i-th alternative point downstream of the Kaliba dam is $x_{i}$, and the water depth is $y_{i}$. Then the cross-sectional area of the river here as:

$$
S_{i}=X_{i} \times Y_{i}
$$

Meanwhile, on the assumption that the unit time passing through any cross-sectional area of the Zambezi water flow rate same. So, you can be selected within the watershed of any crosssectional area equal to two places. That is to say:Si=S.Cross-section of the dam can be seen as a trapezoidal, shown in Fig. 2.

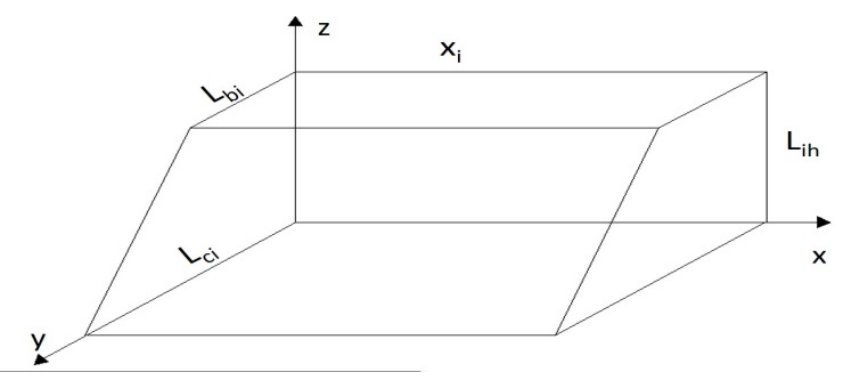

Fig.2: Schematic diagram on the dam

The trapezoidal upperand lower widths are Lbi and Lci, height as Lhi , then the volume of the dam is defined as:

$$
V=x_{i} \frac{\left(L_{b i}+L_{c i}\right) L_{h i}}{2}
$$

To simplify the model, we assume that $\mathrm{kb}$ and $\mathrm{k}_{\mathrm{c}}$ are fixed. It is assumed that in the normal water cycle, the water level is proportional to the height of the dam.The water level of the alternative dam is proportional to the height of the dam.The height of each alternative dam is yi.The dam height required for the unit water level is $\gamma$.Therefore, the height of each dam is defined as: $\quad L_{h i}=\gamma y_{i}$

\subsection{Dam Cost Equation}

Dam costs are associated with a number of factors, and a variety of materials are used in the construction of the dam. In order to facilitate the solution, so here we only consider the use of building materials are mixed uniformly, Where $\beta$ represents the price per unit volume of building materials, and the cost of constructing the dam group is:

$$
C_{l}=\beta V \text {. }
$$

\subsection{Dam Location Selection Basis}

Since the dams we are going to build have the same water management capabilities as the original Kaliba Dam, that is to say, The new dams will not affect the ability of the lower reaches of the Zambezi to transport, irrigate and prevent floods and droughts.We decided to build a new dam system near the original Kaliba Dam.Taking 
into account the Kaliba dam upstream is Kaliba, unable to build dams, So the Kaliba dam and the downstream river construction of new multiple dam system. We use the Global Mapper software to map contours near the Kaliba dam on the Zambezi River,choose the place where the terrain gap is larger, that is, in the contour line-intensive local site to build the dam.Through analysis, as shown in the scatter

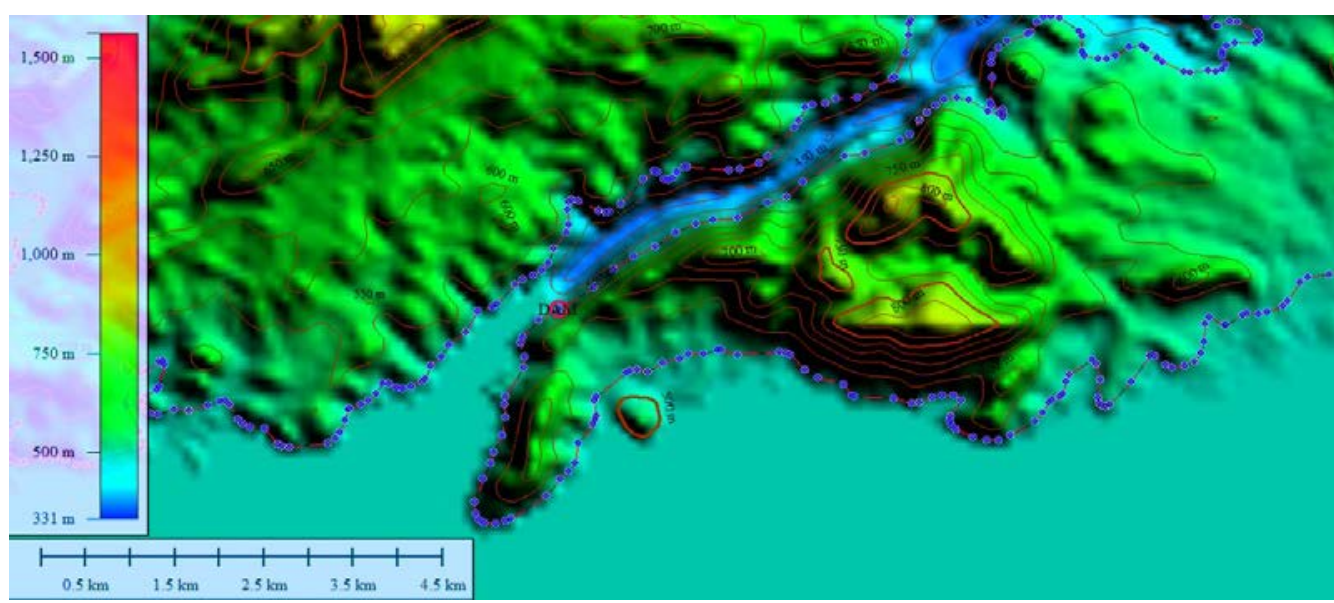

diagram.

Fig.3 Contour map(near the Kaliba dam)

These points is the next possible construction of the dam, that is, alternative addresses.We use the information in the map to calculate the river width xi $(\mathrm{i}=1$, $2, \ldots, 25)$ in the area where the 25 candidate points are located.

\section{0-1 Integer Programming Model (Optimized Addressing Model)}

We use the variable Di to denote whether the i-th alternative address creates a dam[4]. $\mathrm{Di}=0$,if the $\mathrm{i}$ dam is established; $\mathrm{Di}=1$, if the i dam isn't established.

Our task is to choose the right location, in these locations to build $10-20$ dams, so:

$$
10 \leq \sum_{i=1}^{m} D_{i} \leq 20
$$

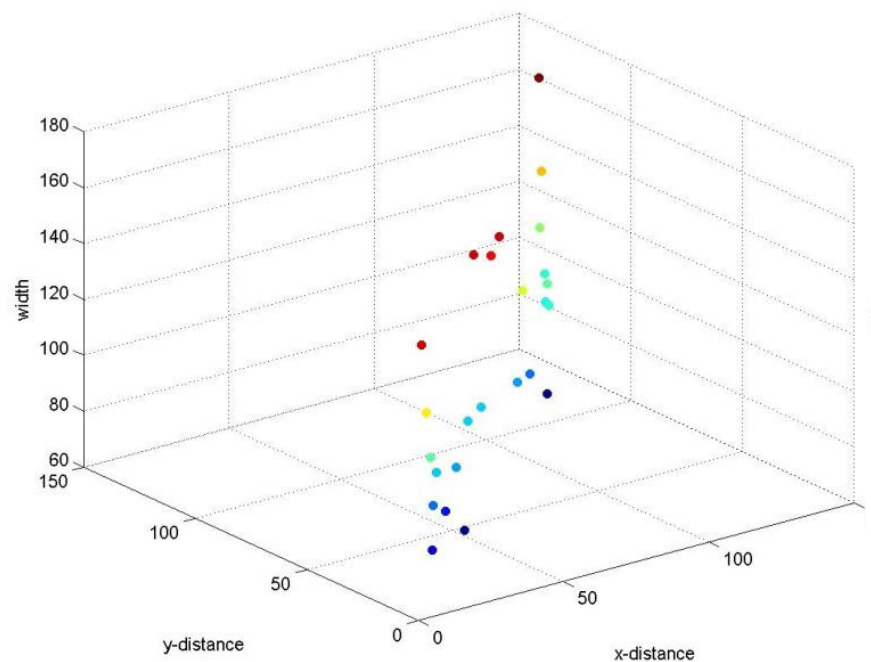

Fig.4: Three-dimensional scatterplot for site selection

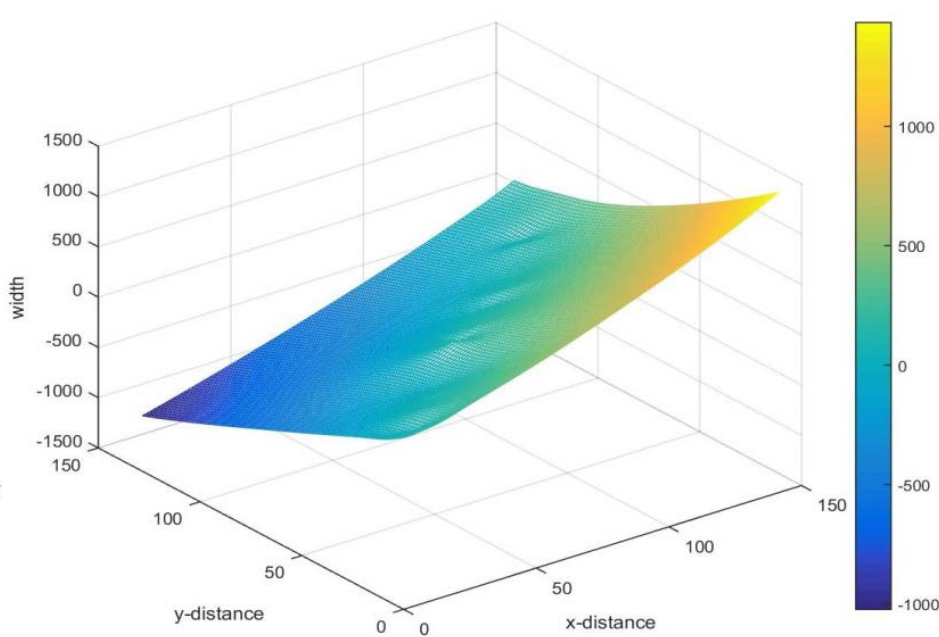

Fig.5: River width three-dimensional surface map

The new dam system is intended to replace the existing Kaliba dam, so the new dam group should have the same capacity as the current Kaliba dam, or even better water 
management capacity, so the new dam group total Of the water level must be met :

$$
\sum_{i=1}^{n} \Delta y_{i} \geq H_{c}
$$

According to the above formula, we can find the construction cost equation of thedam.

$$
C_{l} \not S \quad \frac{\left(k_{b}+k_{c}\right)^{2}}{2} y_{i}
$$

\section{3.conclusion}

Using the above constraint function, the objective function is minimized by using lingo software, and the result is obtained: To obtain the points as shown in the figure 6 ,which represent the number and location of the subsequent construction of the dams.

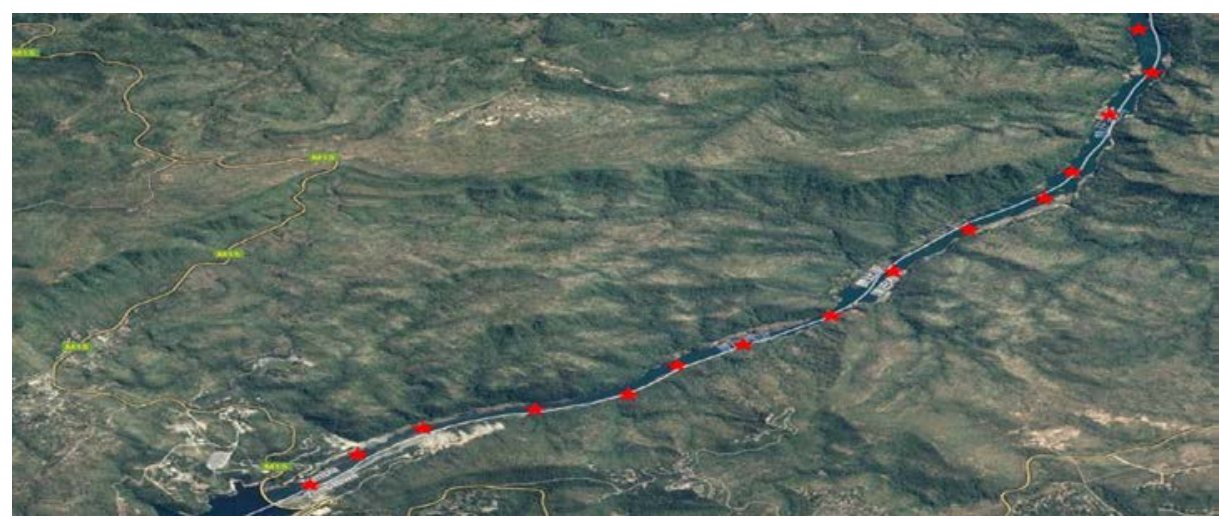

Fig.6 Dam specific location

Table 1: Dam location and river width

\begin{tabular}{cccccc}
\hline Number & 1 & 2 & 3 & 4 & 5 \\
\hline x-distance $/ \mathrm{km}$ & 3.4783 & 10.0000 & 16.5217 & 27.8261 & 40.0000 \\
y-distance/km & 3.0435 & 7.3913 & 14.7826 & 23.9130 & 31.3043 \\
river width & 156.5217 & 113.0435 & 91.3043 & 82.6087 & 69.5652 \\
\hline Number & 6 & 7 & 8 & 9 & 10 \\
\hline x-distance/km & 52.1739 & 61.7391 & 71.3043 & 86.9565 & 99.1304 \\
y-distance/km & 45.6522 & 52.1739 & 56.5217 & 68.6957 & 79.1304 \\
river width & 100.0000 & 100.0000 & 156.5217 & 95.6522 & 91.3043 \\
\hline Number & 11 & 12 & 13 & 14 & 15 \\
\hline x-distance/km & 113.0435 & 116.9565 & 119.5652 & 136.0870 & 143.4783 \\
y-distance/km & 88.6957 & 94.3478 & 98.6957 & 122.6087 & 132.6087 \\
river width & 108.6957 & 113.0435 & 104.3478 & 117.3913 & 165.2174 \\
\hline
\end{tabular}

\section{References}

[1]The Humanistic Environmentb of Zambezi River| baidu. https://www.baidu.com/baidu.com/2012/03/19/ZambeziRiver/

[2] Wenyi Zhang .Study on optimal operation of long - term power generation of Wujiang cascade hydropower station [D]. Xian: Xian University of Technology,2006.

[3] Huitao Zheng. Study and application of parallel solving method for optimal operation of 
hydropower station group [D]. Wuhan: Wuhan University, 2013. 